\title{
Effect of cigarette tax increase in combination with mass media campaign on smoking behaviour in Mauritius: findings from the ITC Mauritius Survey
}

\author{
Sunday Azagba, ${ }^{1,2}$ Premduth Burhoo, ${ }^{3}$ Frank J Chaloupka, ${ }^{4,5,6}$ Geoffrey T Fong ${ }^{7,8,9}$
}

${ }^{1}$ Propel Centre for Population Health Impact, University of Waterloo, Waterloo, Ontario, Canada

${ }^{2}$ School of Public Health and Health Systems, University of Waterloo, Waterloo, Ontario, Canada

${ }^{3}$ Mauritius Institute of Health, Pamplemousses, Mauritius ${ }^{4}$ Department of Economics, University of Illinois at Chicago, Chicago, Illinois, USA ${ }^{5}$ WHO Collaborating Centre on the Economics of Tobacco and Tobacco Control

${ }^{6}$ Health Policy Center, Institute for Health Research and Policy, University of Illinois at Chicago, Chicago, Illinois, USA ${ }^{7}$ Department of Psychology, University of Waterloo,

Waterloo, Ontario, Canada ${ }^{8}$ Ontario Institute for Cancer Research, Toronto, Ontario, Canada

${ }^{9}$ School of Public Health and Health Systems, University of Waterloo, Ontario, Canada

Correspondence to Dr Sunday Azagba, Propel Centre for Population Health Impact, Faculty of Applied Health Sciences, University of Waterloo, 200 University Avenue West, Waterloo, Ontario, Canada N2L 3G1; sazagba@uwaterloo.ca

Received 15 October 2014 Accepted 6 February 2015

Published Online First

20 February 2015

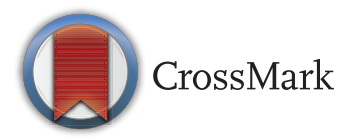

To cite: Azagba $S$

Burhoo P, Chaloupka FJ

et al. Tob Control 2015;24:

iii71-iii75.
ABSTRACT

Background Mauritius has made great strides in adopting evidence-based tobacco control measures, including an increase in its cigarette excise tax and antitobacco mass media (Sponge) campaign. The primary objective of this study is to examine the combined effect of these measures on smoking behaviour.

Methods This study used longitudinal data from the International Tobacco Control Mauritius Survey, 20092011. Waves 1 and 2 were conducted before the tax increase and wave 3 was conducted shortly after the Sponge campaign and 6 months after the cigarette excise tax increase. Generalised estimating equations were used to examine the effects of these two key tobacco control measures on smoking prevalence and the quantity of cigarettes smoked.

Results The results showed that the combination of cigarette tax increase and the Sponge campaign had a significantly negative effect on the prevalence of smoking in Mauritius and the number of cigarettes smoked among continuing smokers. Specifically, the measures significantly reduced the odds of being a smoker (adjusted OR 0.88, 95\% Cl 0.81 to 0.97 ). For average daily cigarettes smoked, the measures had a significant reduction in cigarettes per day by about $6 \%$ (incidence rate ratios $0.94,95 \% \mathrm{Cl} 0.89$ to 0.99 ).

Conclusions The combination of policy measures significantly reduced the consumption of cigarettes in Mauritius. While these results are encouraging, these efforts must be part of a sustained effort to further reduce the smoking prevalence in Mauritius.

\section{INTRODUCTION}

Tobacco use remains the leading cause of preventable death worldwide, with nearly six million deaths attributable to smoking, annually. ${ }^{1}$ About $80 \%$ of smokers live in low and middle income countries (LMICs). ${ }^{1}$ Based on current trends, it is estimated that by 2030 tobacco use will be responsible for more than eight million deaths annually. ${ }^{1}$ Evidence-based tobacco control measures are needed in many jurisdictions, especially in developing countries. ${ }^{2}{ }^{3}$ The policy of increasing tobacco taxes and prices is well documented as the most cost-effective tobacco control intervention and a critical component of a comprehensive tobacco control strategy. ${ }^{4-6}$ Article 6 of the WHO Framework Convention on Tobacco Control (FCTC) obligates countries that have ratified the treaty to use tax and price policies to reduce tobacco consumption. ${ }^{7}$ Higher tobacco taxes are effective for promoting cessation, preventing initiation and reducing consumption, and also provide significant government revenue. Antitobacco mass media campaigns have similarly been shown to be an effective population-wide intervention tool, especially when combined with other tobacco control measures. ${ }^{8-11}$

Mauritius has made great strides in adopting evidence-based tobacco control measures. The WHO FCTC was signed by Mauritius in June 2003 and ratified in May 2004. In collaboration with the WHO and several other stakeholders, the Mauritian government developed a National Action Plan on Tobacco Control from 2008 through 2012. The main objective of this Action Plan was to reduce tobacco-related mortality and morbidity by preventing the use of tobacco products, promoting cessation and reducing second-hand smoke exposure. Results from the 2008 Mauritius Non-Communicable Diseases Survey found that the adult smoking prevalence in Mauritius in 2008 was $40.3 \%$ for men and $3.7 \%$ for women, which is among the highest smoking prevalence rates in Africa. ${ }^{12}$ To address this high smoking prevalence, Mauritius passed the Public Health (Restrictions on Tobacco Products) Regulations 2008, which updated its 1999 policies on smoking in public places; packaging and labelling of tobacco products; tobacco advertising, promotion and sponsorship; and illicit trade. These 2008 restrictions on tobacco products were implemented in two phases. In phase one, regulations to strengthen policies on smoking in public places, illicit trade (eg, the display of official excise stamps and a provision requesting that cigarette packs carry a statement-'sale allowed in Mauritius only') and tobacco advertising, promotion and sponsorship, were implemented on 1 March 2009. Regulations on pictorial warning labels (occupying $65 \%$ of the pack's area), packaging descriptors and banning the sale of single cigarettes followed on 1 June 2009.

While evidence on the effectiveness of tobacco control measures in LMICs using individual-level data is accumulating, many previous studies have used macrodata /time series data. ${ }^{4}$ The hesitation of LMIC's policymakers to adopt tobacco control measures based on results from high income countries contributed to the growth of LMIC studies since the early 2000s. ${ }^{13-16}$ Owing to a lack of individual-level data in Mauritius, there is limited evidence on the effect of tobacco control measures on smoking behaviour.

The International Tobacco Control Policy Evaluation (ITC) Mauritius Project offers a unique and timely opportunity to fill this gap. The primary objective of this study is to examine the combined 
Table 1 Mauritius cigarette tax structure, 2007-2011

\begin{tabular}{|c|c|c|c|c|c|}
\hline & $\begin{array}{l}\text { Excise duty } \\
\text { (MUR per } 1000 \text { stick) }\end{array}$ & Customs duty* (\%) & $\begin{array}{l}\text { Ad valorem excise } \\
\text { taxt }(\%)\end{array}$ & VAT $(\%)$ & Remarks \\
\hline \multirow[t]{4}{*}{ 2007-2008 } & 2370 & 30 & & 15 & Category A \\
\hline & 1770 & 30 & & 15 & Category B \\
\hline & 2010 & & 30 & 15 & Category C \\
\hline & 2130 & & 30 & 15 & Category D \\
\hline 1 July 2008-19 November 2010 & 2200 & Nil & & 15 & Only one category \\
\hline 20 November 2010-4 November 2011 & 2750 & Nil & & 15 & Only one category \\
\hline 5 November 2011-9 November 2012 & 3160 & Nil & & 15 & Only one category \\
\hline 10 November 2012 & 3540 & Nil & & 15 & Only one category \\
\hline \multicolumn{6}{|c|}{$\begin{array}{l}\text { Source: Mauritius Revenue Authority. } \\
\text { Category A: cigarettes at the top-end of the international markets: foreign brands (eg, Benson \& Hedges, Camel, Dunhill, Marlboro). } \\
\text { Category B: other foreign cigarettes not classified under category A. } \\
\text { Category C: local cigarettes. } \\
\text { Category D: other cigarettes not classified under A, B or C and whether containing tobacco or not. } \\
{ }^{*} \text { Customs duty applies to imported cigarettes based on CIF value. } \\
\text { †Ad valorem (sales tax) applies to locally produced cigarettes based on ex-factory price. } \\
\text { CIF, cost, insurance and freight; MUR, Mauritian Rupees; VAT, value-added tax. }\end{array}$} \\
\hline
\end{tabular}

effect of cigarette excise tax increase and an antitobacco mass media campaign on smoking prevalence and quantity of cigarettes smoked using longitudinal data from the ITC Mauritius Project (2009-2011). The Mauritian Ministry of Health and Quality of Life launched the Sponge campaign, a national antitobacco mass media campaign in May, 2011, with technical and financial support from the World Lung Foundation (WLF). 'Sponge' was first created as part of a national health awareness campaign, focusing on the negative effects of smoking in Sydney, Australia. ${ }^{11}$ The WLF has promoted the Sponge campaign worldwide in order to graphically illustrate the harmful effect of smoking on smokers' lungs. The Mauritian Sponge campaign used television, radio and billboards, with messages in local languages (Creole and Bhojpuri) to warn smokers and nonsmokers about health risks of tobacco use.

\section{METHODS}

Data

The ITC Mauritius Project was started in 2009 to evaluate the impact of tobacco control legislation in Mauritius. The ITC Mauritius Survey is part of the larger ITC Project, conducted in more than 20 countries, primarily to evaluate WHO FCTC policies. ${ }^{17} 18$ The ITC Mauritius Survey is a nationally representative longitudinal face-to-face survey of adult smokers and non-smokers in Mauritius. Smokers were adults (aged $\geq 18$ years) who reported having smoked at least 100 cigarettes in their life, and had smoked at least once in the previous 30 days. The survey is based on a stratified multistage sampling framework, where respondents were randomly selected from households within strata defined by the nine geographic districts of Mauritius. This sampling procedure accounts for the urbanrural population split in Mauritius (43\% urban and 57\% rural). Waves 1 and 2 were conducted in April-May 2009 and AugustSeptember 2010, respectively (before the tax increase). Wave 3 was conducted in June-July 2011 (6 months after excise tax increased by $25 \%$ and approximately 1 month after the Sponge campaign). In wave 1, a total of 598 smokers and 239 nonsmokers were surveyed. In wave 2, a total of 601 smokers and 239 non-smokers were surveyed. In wave 3, a total of 602 smokers and quitters and 238 non-smokers were recontacted and successfully reinterviewed. The retention rate at wave 3 was 96.2\% for smokers and $95.8 \%$ for non-smokers. These retention rates are exceptionally high among longitudinal cohort surveys (on average, the retention rate of the ITC survey is between $75 \%$ and $80 \%$ ). In the present study, we restricted our analysis to a balanced panel (surveyed in all three waves and with no missing observation), yielding 725 respondents and 2175 person-year observations. Of the 725 respondents included in our analysis, about $67 \%$ were current smokers (521 in wave 1, 477 in wave 2 and 462 in wave 3) and 33\% were non-smokers (204 in wave 1, 248 in wave 2 and 263 in wave $3)$. Owing to the high retention rate, attrition bias is highly unlikely; however, to test for non-response bias, we used the simple addition variable test suggested by Verbeek and Nijman. ${ }^{19}$ We created two variables reflecting survey response patterns: a dummy indicating if an individual responds in the next wave, and also a dummy showing whether the individual responds in all waves. We used probit regression for smoking participation and linear regression for number of cigarettes using the unbalanced sample with each of the response variables included. As expected, the results did not reject the null hypothesis of no attrition bias at the $10 \%$ significance level.

The survey and research protocol was reviewed and given ethical clearance by the Office of Research Ethics, University of Waterloo, and the Mauritius National Ethics Committee.

\section{Mauritius cigarette tax structure}

Table 1 shows the cigarette tax structure over time in Mauritius. Prior to 2008, a combination of ad valorem and specific excise taxes was levied on all locally produced cigarettes as well as value-added tax (VAT). Imported cigarettes had custom and excise duties as well as VAT (see Shang et al, ${ }^{20}$ for a crosscountry comparison). After domestic tobacco manufacturing stopped in 2008, only imported cigarettes were sold. In July 2008, a specific excise tax of Mauritian Rupees (MUR) 2200 $(\text { US\$70.00) })^{\mathrm{i}}$ was imposed per 1000 sticks of cigarettes and VAT of $15 \%$ on the sum of excise tax and the base cost of cigarettes. In November 2010, excise tax increased by $25 \%$ to MUR 2750 (US\$88.00). In November 2011, excise tax increased by $15 \%$ to MUR 3160 (US\$101.00) and increased again in November 2012 by $12 \%$ to MUR 3540 (US\$113.00). The VAT has remained at $15 \%$ of the VAT-exclusive price to the consumer.

${ }^{\mathrm{i}}$ Exchange rate (1 MUR to US\$0.032) as on 15 December 2014 from xe.com 


\section{Empirical strategy}

To examine the combined effect of cigarette tax increase and Sponge campaign on the smoking behaviour of individuals, we used the following approach

$$
\mathrm{Y}_{\mathrm{it}}=\beta_{0}+\beta_{1} \text { Policy }_{\mathrm{t}}+\beta_{2} \mathrm{X}_{\mathrm{it}}+\varepsilon_{\mathrm{it}}
$$

where $\mathrm{Y}_{\text {it }}$ represents individual smoking outcomes (smoking participation and average daily number of cigarettes) at survey time t. The variable Policy ${ }_{t}$, key variable of interest, is a dummy variable that captures the increase in cigarette tax and the implementation of the Sponge campaign. The Policy variable was zero for all individuals for survey years 2009 (wave 1) and 2010 (wave 2) since both waves were completed before the measures were implemented. In wave 3 (survey year 2011), Policy $y_{t}$ equalled one for all individuals. Both measures did not occur simultaneously, but using a dummy variable to account for the combined effect is logical given that wave 3 of the ITC Mauritius Survey (June-July 2011) almost coincided with the Sponge campaign. ${ }^{\mathrm{ii}}$ For the smoking participation outcome, $\beta_{2}$ represents the average change in the probability of smoking between prepolicy and postpolicy periods. In estimating the daily number of cigarettes smoked, $\beta_{1}$ indicates the average change in the number of cigarettes smoked daily. The analysis also controlled for individual sociodemographic characteristics, vector $\mathrm{X}_{\mathrm{it}}$, including age, gender, education, income, marital status and employment status.

Population-averaged panel data model was estimated using generalised estimating equations (GEE) with a link function (logit) and a family distribution (binomial) for the binary outcome, and a link function (log) and a family distribution (Poisson) for number of cigarettes. ${ }^{21}$ A flexible working correlation structure (unstructured correlation) was used in the GEE estimations. The regression analysis was population weighted using the survey weights in order to adjust for unequal probabilities of selection between smokers and non-smokers.

\section{RESULTS}

Table 2 shows the average sample characteristics for waves 1-3. Of the 725 respondents included in our analysis, the majority of the participants were males (76\%), married (75\%), completed at least school (56\%) and had a household monthly income of less than MUR 15000 (US\$480.00). The weighted data (not reported) showed that $32.2 \%$ of males and $2.8 \%$ of females in wave $1,30.6 \%$ males and $2.5 \%$ females in wave 2, and $28.6 \%$ males and $2.39 \%$ females in wave 3 were smokers. Among smokers, the average cigarettes smoked per day (CPD) was 9.12 in wave 1, 9.64 in wave 2 and 8.94 in wave 3 .

Tables 3 and 4 show the estimation results from the GEE model. In table 3, we examine the effect of the tax increase in combination with antitobacco national media campaign on smoking participation and CPD using data from waves $1-3$. The results showed that the combination of policy measures significantly reduced the prevalence of smoking in Mauritius and the number of cigarettes smoked among continuing smokers. The odds of being a smoker fell by about $12 \%$ as a result of the policy measures (adjusted OR (AOR) 0.88, 95\% CI 0.81 to $0.97)$. For average daily cigarettes smoked, the policy reduced
Table 2 Average sample characteristics, 2009-2011

\begin{tabular}{|c|c|c|}
\hline & $\begin{array}{l}\text { Unweighted } \\
\text { Mean/proportion }\end{array}$ & $\begin{array}{l}\text { Weighted } \\
\text { Mean/proportion }\end{array}$ \\
\hline \multicolumn{3}{|l|}{ Sex } \\
\hline Male & 0.757 & 0.759 \\
\hline Female & 0.243 & 0.241 \\
\hline \multicolumn{3}{|l|}{ Age } \\
\hline $18-24$ & 0.078 & 0.100 \\
\hline $25-39$ & 0.328 & 0.335 \\
\hline $40-54$ & 0.377 & 0.332 \\
\hline 55 or more & 0.217 & 0.233 \\
\hline \multicolumn{3}{|l|}{ Education } \\
\hline Some/completed university & 0.112 & 0.114 \\
\hline Form 1-4/SC completed & 0.445 & 0.431 \\
\hline Primary school or less & 0.443 & 0.455 \\
\hline \multicolumn{3}{|l|}{ Income } \\
\hline MUR 30000 or more & 0.076 & 0.080 \\
\hline MUR 15 000-29 999 & 0.259 & 0.270 \\
\hline Less than MUR 15000 & 0.665 & 0.650 \\
\hline \multicolumn{3}{|l|}{ Marital status } \\
\hline Married & 0.745 & 0.707 \\
\hline Separated/widowed & 0.096 & 0.100 \\
\hline Single & 0.159 & 0.193 \\
\hline Employed & 0.771 & 0.772 \\
\hline Unemployed/inactive & 0.229 & 0.228 \\
\hline
\end{tabular}

the average number of CPD by $6 \%$ (incidence rate ratios (IRR) $0.94,95 \%$ CI 0.89 to 0.99 ). Given that the increase in cigarette tax and the Sponge campaign were the main tobacco control measures implemented between 2010 and 2011, ${ }^{\text {iii }}$ we restricted our analysis by using data from waves 2 to 3 and the results are shown in table 4. Similar results were found, with the policy having significant effects on smoking participation (AOR 0.85, $95 \%$ CI 0.76 to 0.95 ) and daily number of cigarettes consumed (IRR $0.94,95 \%$ CI 0.88 to 1.00 ).

\section{DISCUSSION}

The current study provides empirical evidence that the cigarette tax increase in combination with antitobacco national media campaign implemented in Mauritius, had significant effects on smoking behaviour. The policy measures significantly reduced the odds of being a smoker by about $12 \%$ and reduced average CPD by about $6 \%$. Our findings are consistent with prior research showing that mass media campaigns are effective when combined with other tobacco measures. ${ }^{8-10}$ For example, a recent review study by Durkin $e t a l^{8}$ found consistent evidence that mass media campaigns are particularly effective in reducing adult smoking prevalence when conducted as part of a comprehensive tobacco control programme. Similarly, results from a time series analysis showed that increases in cigarette costliness and exposure to tobacco control media campaigns significantly reduced smoking prevalence in Australia. ${ }^{9}$ Our finding is also in keeping with a recent ITC Mauritius report indicating that the Sponge campaign was successful in reaching smokers and non-smokers. ${ }^{22}$

\footnotetext{
ii Owing to the limited variability in self-reported prices at the primary sampling unit level (local district level), we were not able to estimate price elasticity by using the price variable in the regression.
}

iii Of note, wave 3 of the ITC Mauritius Survey was conducted before government supported cessation clinics were implemented in November, 2011. 
Table 3 GEE estimates for prevalence of cigarette smoking and number of cigarettes smoked daily, 2009-2011

\begin{tabular}{|c|c|c|c|c|}
\hline & \multicolumn{2}{|c|}{ Smoking participation } & \multicolumn{2}{|c|}{$\begin{array}{l}\text { Average daily } \\
\text { cigarettes }\end{array}$} \\
\hline & AOR & $95 \% \mathrm{Cl}$ & IRR & $95 \% \mathrm{Cl}$ \\
\hline Policy & $0.88^{* * *}$ & 0.80 to 0.96 & $0.94^{* *}$ & 0.89 to 0.99 \\
\hline Male & $13.95^{* * *}$ & 8.26 to 23.58 & 1.09 & 0.92 to 1.29 \\
\hline Age & $0.99^{*}$ & 0.97 to 1.00 & $1.00^{*}$ & 1.00 to 1.01 \\
\hline \multicolumn{5}{|l|}{ Education } \\
\hline Some/completed university & 0.77 & 0.55 to 1.08 & 0.89 & 0.68 to 1.15 \\
\hline Form 1-4/SC completed & 0.87 & 0.69 to 1.10 & 1.04 & 0.95 to 1.14 \\
\hline Primary school or less & 1 & & 1 & \\
\hline \multicolumn{5}{|l|}{ Income } \\
\hline MUR 30000 or more & 0.66 & 0.39 to 1.10 & 1.08 & 0.88 to 1.33 \\
\hline MUR 15 000-29 999 & $1.09^{*}$ & 0.98 to 1.22 & 1.05 & 0.95 to 1.15 \\
\hline Less than MUR 15000 & 1 & & 1 & \\
\hline \multicolumn{5}{|l|}{ Marital status } \\
\hline Married & 1.16 & 0.87 to 1.55 & 1.08 & 0.91 to 1.28 \\
\hline Separated/widowed & 1.14 & 0.86 to 1.53 & 1.17 & 0.96 to 1.44 \\
\hline Single & 1 & & 1 & \\
\hline Employed & 1.14 & 0.89 to 1.46 & $1.25^{* * *}$ & 1.11 to 1.41 \\
\hline Unemployed/inactive & 1 & & 1 & \\
\hline \multicolumn{5}{|c|}{$\begin{array}{l}\text { The sample includes } 725 \text { respondents, yielding } 2175 \text { person-year observations. For } \\
\text { the CPD analysis, the sample includes } 521 \text { smokers, yielding } 1460 \text { person-year } \\
\text { observations. } \\
{ }^{*} p<0.1,{ }^{* *} p<0.05,{ }^{* * *} p<0.01 \text {. } \\
\text { AOR, adjusted OR; CPD, cigarettes smoked per day; GEE, generalised estimating } \\
\text { equations; IRR, incidence rate ratios; MUR, Mauritian Rupees; SC, school certificate. }\end{array}$} \\
\hline
\end{tabular}

The study has some limitations. First, the data are selfreported, which may introduce recall and social desirability biases. Second, the observed changes may not be attributed only

Table 4 GEE estimates for prevalence of cigarette smoking and number of cigarettes smoked daily, 2010-2011

\begin{tabular}{|c|c|c|c|c|}
\hline & \multicolumn{2}{|c|}{ Smoking participation } & \multicolumn{2}{|c|}{$\begin{array}{l}\text { Average daily } \\
\text { cigarettes }\end{array}$} \\
\hline & AOR & $95 \% \mathrm{Cl}$ & IRR & $95 \% \mathrm{Cl}$ \\
\hline Policy & $0.85^{* * *}$ & 0.76 to 0.94 & $0.94 * *$ & 0.88 to 1.00 \\
\hline Male & $13.37^{* * *}$ & 7.93 to 22.57 & 1.15 & 0.92 to 1.43 \\
\hline Age & $0.98 *$ & 0.97 to 1.00 & $1.01 * *$ & 1.00 to 1.01 \\
\hline \multicolumn{5}{|l|}{ Education } \\
\hline Some/completed university & $0.54^{* *}$ & 0.33 to 0.88 & 0.94 & 0.70 to 1.26 \\
\hline Form 1-4/SC completed & $0.72^{*}$ & 0.50 to 1.02 & 1.01 & 0.90 to 1.12 \\
\hline Primary school or less & 1 & & 1 & \\
\hline \multicolumn{5}{|l|}{ Income } \\
\hline MUR 30000 or more & 0.76 & 0.48 to 1.21 & 1.07 & 0.85 to 1.35 \\
\hline MUR 15 000-29 999 & 1.09 & 0.96 to 1.24 & 1.05 & 0.94 to 1.17 \\
\hline Less than MUR 15000 & 1 & & 1 & \\
\hline \multicolumn{5}{|l|}{ Marital status } \\
\hline Married & 1.06 & 0.68 to 1.65 & 1.09 & 0.89 to 1.32 \\
\hline Separated/widowed & 1.05 & 0.64 to 1.72 & 1.06 & 0.82 to 1.38 \\
\hline Single & 1 & & 1 & \\
\hline Employed & $1.25^{*}$ & 0.96 to 1.56 & $1.24^{* *}$ & 1.06 to 1.46 \\
\hline Unemployed/inactive & 1 & & 1 & \\
\hline
\end{tabular}

to the tax increase and the national mass media campaign. While no new policies were implemented between waves 2 and 3 except for the tax rate revision and an antismoking media campaign, to what extent our results, in part, reflect other tobacco measures, is unknown. Third, our estimate may also reflect a potential underlying downward trend in smoking prevalence, and we were unable to control for time trend due to collinearity between the policy variable and the inclusion of survey year. Finally, the ITC survey does not have data to measure the impact of increased taxation on underage smokers and smoking initiation among youth.

In conclusion, the 2010 increase in cigarette taxes and prices had a significant effect on smoking behaviour by reducing smoking prevalence and smoking intensity in continuing smokers. These results are particularly encouraging given the strong commitment of the Mauritian government in implementing evidence-based tobacco control measures. The findings shown in this study provide important policy and practice considerations, especially for policymakers in developing countries. While there is no one-size-fits-all tobacco control measure, other African countries can potentially benefit from the Mauritian experience.

\section{What this paper adds}

- Mauritius has implemented evidence-based tobacco control measures. While the evidence of tobacco control policies is accumulating in Africa, not much is known about the effects of these regulations in Mauritius.

- This study showed that an increase in cigarette taxes, in combination with other WHO Framework Convention on Tobacco Control (FCTC) tobacco control policies implemented in Mauritius, significantly reduced cigarette smoking.

- These results may be useful for policy intervention in other developing countries, especially in Africa.

\begin{abstract}
Acknowledgements The authors would like to acknowledge the ITC Mauritius team for its contributions in planning and implementing the ITC Mauritius Survey, and the fieldwork team that conducted the interviews.
\end{abstract}

Contributors SA designed the study, analysed the data, interpreted the results and drafted the manuscript. PB is the principal investigator of the ITC Mauritius Project and contributed to the draft. FJC participated in the study design, analysis and interpretation of the data. GTF is the chief investigator of the ITC Project and contributed to the study design. All authors contributed to successive drafts. The final manuscript was approved by all authors.

Funding This research was funded by the International Development Research Centre (Waves 1 and 2), and partially funded by the Bloomberg Global InitiativeInternational Union Against Tuberculosis and Lung Disease (Wave 3), and the World Lung Foundation (Wave 3). Support was also provided by the Canadian Institutes of Health Research (79551 and 115016) and the US National Cancer Institute (P01 CA138389 and P50 CA111236). Additional support was provided to GTF from a Senior Investigator Award from the Ontario Institute for Cancer Research and a Prevention Scientist Award from the Canadian Cancer Society Research Institute.

\section{Competing interests None.}

Ethics approval The ITC Mauritius Survey was cleared for ethics by Research Ethics Boards or International Review Boards at the University of Waterloo, Canada, and Mauritius Institute of Health, Mauritius.

Provenance and peer review Not commissioned; externally peer reviewed.

\section{REFERENCES}

1 World Health Organization. Tobacco fact sheet. 2014. http://www.who.int/ mediacentre/factsheets/fs339/en/ 
2 Warner KE, Tam J. The impact of tobacco control research on policy: 20 years of progress. Tob Control 2012;21:103-9.

3 Van Walbeek C, Blecher E, Gilmore A, et al. Price and tax measures and illicit trade in the framework convention on tobacco control: what we know and what research is required. Nicotine Tob Res 2013;15:767-76.

4 IARC. IARC Handbooks of Cancer Prevention: Tobacco Control. Volume 14. Effectiveness of price and tax policies for control of tobacco. Lyon, France: International Agency for Research on Cancer, 2011.

5 Chaloupka FJ, Warner KE. The economics of smoking. Handb Health Econ 2000;1:1539-627.

6 Chaloupka FJ, Yurekli A, Fong GT. Tobacco taxes as a tobacco control strategy. Tob Control 2012;21:172-80.

7 World Health Organization. 2012 global progress report on implementation of the WHO Framework Convention on Tobacco Control. World Health Organization, 2012.

8 Durkin S, Brennan E, Wakefield M. Mass media campaigns to promote smoking cessation among adults: an integrative review. Tob Control 2012;21:127-38.

9 Wakefield MA, Durkin S, Spittal MJ, et al. Impact of tobacco control policies and mass media campaigns on monthly adult smoking prevalence. Am J Public Health 2008;98:1443.

10 Wakefield MA, Loken B, Hornik RC. Use of mass media campaigns to change health behaviour. Lancet 2010;376:1261-71.

11 Cotter T, Hung WT, Perez D, et al. Squeezing new life out of an old Sponge: how to modernise an anti-smoking media campaign to capture a new market. Aust N Z J Public Health 2011;35:75-80.

12 Republic of Mauritius, Ministry of Health and Quality of Life. The Trends in Diabetes and Cardiovascular Disease Risk in Mauritius: The Mauritius Non Communicable Diseases Survey 2009. 2009. http://www.gov.mu/portal/goc/moh/file/ncd/ncd-2009.pdf
13 Aloui O. Analysis of the economics of tobacco in Morocco. HNP Discussion Paper Series, Economics of Tobacco Control Paper No.7. Washington DC: The World Bank, 2003.

14 Ali Z, Rahman A, Rahman T. Appetite for nicotine: an economic analysis of tobacco control in Bangladesh. HNP Discussion Paper Series, Economics of Tobacco Control Paper No.16. Washington DC: The World Bank, 2003.

15 Hu T, Mao Z. Economics analysis of tobacco and options for tobacco control. HNP Discussion Paper Series, Economics of Tobacco Control Paper No.3. Washington DC: The World Bank, 2002

16 Guindon GE, Perucic AM, Boisclair D. Higher tobacco prices and taxes in South-East Asia: an effective tool to reduce tobacco use, save lives and generate revenue. HNP Discussion Paper Series, Economics of Tobacco Control Paper No.11. Washington DC: The World Bank, 2003.

17 Fong GT, Cummings KM, Borland R, et al. The conceptual framework of the International Tobacco Control (ITC) policy evaluation project. Tob Control 2006;15 (Suppl 3):iii3-11.

18 Thompson ME, Fong GT, Hammond D, et al. Methods of the International Tobacco Control (ITC) four country survey. Tob Control 2006;15(Suppl 3):iii12-18.

19 Verbeek M, Nijman TE. Testing for selectivity bias in panel data models. Int Econ Rev 1992;33:681-703.

20 Shang C, Chaloupka FJ, Zahra N, et al. The distribution of cigarette prices under different tax structures: findings from the International Tobacco Control Policy Evaluation (ITC) Project. Tob Control 2014;23(Suppl 1):i23-9.

21 Liang KY, Zeger SL. Longitudinal data analysis using generalized linear models. Biometrika 1986;73:13-22.

22 ITC Project. ITC Mauritius National Report-Results of the Wave 3 Survey. Ontario, Canada: University of Waterloo; Pamplemousses, Mauritius: Mauritius Institute of Health (MIH), 2012 